\title{
Acquiring Multilingualism at School. What Translation Tasks Tell Us about Adolescents' Use of the Multilingual Lexicon
}

\author{
Lies Sercu \\ Faculty of Arts, Katholieke Universiteit Leuven (K.U. Leuven), \\ Blijde-Inkomststraat 21, 3000 Leuven, Belgium
}

In this article, we report on an investigation that aimed to describe adolescent multilinguals' use of the different languages they were learning at school when performing a translation task. We wanted to find out whether written translations of a mother tongue text into the learner's different foreign languages would reflect a multilingual rather than a bilingual mode of language processing and production. We found that the extent of cross-linguistic influence was limited, and that our respondents, in most cases, managed to activate the appropriate target language only. When cross-linguistic influence occurred, it showed evidence of the activation of mainly two, and sometimes three, languages. Our findings also show that the extent of cross-linguistic influence is related to proficiency, psychotypology, the specific language combination (e.g. Dutch-French-English-German) and frequency of use, and that learners use different strategies to make up for lexical gaps in their knowledge.

doi: $10.2167 /$ ijm056.0

Keywords: cross-linguistic influence, multilingual lexicon, translation task

\section{Introduction}

The fact that the majority of the world's population is multilingual has only recently attracted the attention of language acquisition researchers. Studies of multilingualism have emphasised the need to conduct specific research that goes beyond inquiring into the acquisition of one foreign language (Cenoz et al., 2001b, 2003), which focuses specifically on the interconnections between the various lexicons in the multilingual's mind and on instances of crosslinguistic influence (CLI) between a multilingual's different languages.

Research on multilingualism is more complex than research on bilingualism. It has to take account of the findings concerning the acquisition of a first foreign language, and find ways to investigate the way in which multilinguals store, access, activate, manage and use their different languages. Today, the idea that a bilingual's different lexicons are not stored separately in the brain, but are interconnected and can be activated in parallel, is generally accepted. In addition, all current accounts (e.g. Dijkstra \& Van Heuven, 1998; Heuven, 2002; Green, 1998; Paradis, 1997) suppose regulation of this complex system by controlling the level of activation of the different languages at the meaning, 
lemma or lexeme level, though details concerning the locus where and the mechanisms with which parts of languages may be inhibited or activated may vary. Building on these findings, research of multilingualism has to determine to what extent this theoretical representational model of the bilingual brain adequately reflects the way in which a multilingual brain operates. Thus, it has to answer questions, such as 'Does the idea of interconnectivity apply to language pairs only (e.g. L1-L2) or also to language triplets (e.g. L1-L2-L3; L2L3-L4) or quadruplets?' or 'Do multilingual learners manage to keep their different languages apart or does their language production show more frequent instances of cross-linguistic influence?' or 'Do the same learner factors that have been shown to affect the extent of cross-linguistic influence in bilinguals, such as psychotypology, L2 status or recency of use, apply to multilinguals as well?'

In this article, we report on an investigation that aimed to describe how multilinguals use the different languages they were learning at school when performing a translation task. What we wanted to find out was whether written translations from a mother tongue text into the learner's different foreign languages would reflect a multilingual rather than a bilingual mode of language processing and production. In a bilingual mode, cross-linguistic influence would mainly happen between the source language and one target language. In a multilingual mode, the texts would show evidence of the simultaneous activation of more than two languages. In addition, we wanted to find out which variables appeared to affect the extent of cross-linguistic influence, as well as which cross-linguistic strategies (loanwords, loanblends, literal translations) learners appeared to use when confronted with a lexical gap in their knowledge.

Before enlarging on the details of our research design, we first present a summary of the way in which the multilingual lexicon is currently conceived of and, in this light, discuss the translation task which was used in this study to gain access to the multilingual lexicon. Next, we provide a brief overview of some of the major findings regarding the different variables which previous research has found to affect cross-linguistic influence, focusing in particular on the variables that are relevant to our own study.

\section{Structure of the bi-/multilingual lexicon}

Two questions concerning the bi-/multilingual lexicon continue to fascinate researchers: (1) is lexical information stored in one big lexicon containing all the words of all the languages an individual knows, or are there separate lexicons for these different languages?; (2) how are the different languages in the multilingual brain regulated and controlled?

\section{(1) One big lexicon versus separated lexicons}

Not too long ago, it was assumed that bilinguals had two independent language recognition and production systems, one for their first language and a second one for their second language. 'The received wisdom used to be that the L1 mental lexicon was qualitatively different from, and therefore, by implication, separate from, the mental lexicons associated with any additional 
languages (...)' (Singleton, 2003: 167). Using a spatial metaphor, as opposed to the activation metaphor that is currently in vogue (cf. infra), it was assumed that the different lexicons were located in different parts of the brain. This kind of model can explain why bilinguals, or by extension multilinguals, can read a book in one language and not be hindered by their other language(s) (Brysbaert, 1998; s.d.). Over the years, more sophisticated models have been proposed, such as the Hierarchical model and the Revised Hierarchical model (Kroll \& Curley, 1988; Kroll \& Stewart, 1994; Kroll \& de Groot, 1997), where the underlying assumption remains that there are independent lexicons for the words in each language, but that there is one common conceptual system, i.e. that lexicons are linked at the level of meaning. A recent development within the Hierarchical model concerns the representation of meaning as a bundle of characteristics. The fact that a concept falls apart into a bundle of meaning characteristics, makes it possible to activate a slightly different combination of characteristics in one language than in the other language. In this way, the meaning of words can easily be different from one language to the next (Kroll \& de Groot, 1997).

Today, this idea of spatial separation and independent lexicons for the words in each language, albeit that they are linked at the conceptual level, is no longer accepted. It is indeed relatively easy to find arguments in favour of a high degree of interlexical connectivity. The fact that cross-linguistic influence exists at all demonstrates such connectivity beyond doubt. Psycholinguistic evidence has shown that learners are unable to suppress lexicons wholly. While recognising a word in the second language, similar words in the first language may even be more important than similar words in that second language (Brysbaert et al., 1999; Dijkstra et al., 2000; Van Heuven et al., 1998).

Recent models are mostly based on connectionist models consisting of networks, in which each entry may be connected to one or many other entries, similar to what we know about neural networks (de Bot et al., 2005: 42). Almost all models today are based on this connectionist principle, combined with the idea that entries in the lexicon may vary in their degree of activation. One activation model that is on the rise, is the Bilingual Interactive Activation model (BIA-model) (Dijkstra et al., 1998; Van Heuven et al., 1998). This computer model incorporates an integrated lexicon with words from two different languages rather than one. The model departs from an activation metaphor, instead of a spatial metaphor (cf. supra), and views activation of the lexical representations as language non-specific and as happening on the basis of similarities between the offered letter stimulus and the stored lexical representations. Thus, the letter combination must will activate the English word must but also to a lesser extent Dutch and/or English words, such as bust, dust, fust, gust, just, kust, lust, oust, rust, mast, mest, mist, most, munt, mutt, muse, mush, musk and muss. All activated lexical candidates, possibly from different languages, will compete with each other and suppress each other's activation until the appropriate 'winner' surfaces. Words may be interconnected via semantic, phonological or orthographic features, and via a language tag. With the help of a language node, the system sees to it that a stimulus from a specific language activates the words from that language more strongly and inhibits the words from the other language. The BIA model accounts for 
asymmetries observed in unbalanced bilinguals in terms of resting level activations, which are generally lower for words in L2 than L1. As a consequence, L2 words on the whole become activated more slowly and to a lesser extent than L1 words.

When applying the BIA model to multilingualism, the scope for the conception of organisational arrangements becomes very much larger, and vastly more complex, given the additional number of lexical candidates from different languages that can be activated. It has also been suggested that exposure to additional foreign languages results in weaker connections to the semantic representations in each language by adding more noise to the whole system. An obvious explanation for this effect is that the concurrent study of several foreign languages can lead to a dilution in attentional resources during the learning process. This is in accordance with multilingual interactive activation models (Grainger \& Dijkstra, 1992; Keatley et al., 1994) in that they suggest that the strength of intralingual connections needs to be developed slowly over time. If a student is exposed to both Russian and French vocabulary simultaneously, it will take some time to strengthen the links of each Russian word to the other Russian words and each French word to the other French words, so that these links will come to dominate over any potential links between languages or against background noise (Kempe \& MacWhinney, 1996: 39).

\section{(2) Proactive versus retroactive control of activation levels}

All current accounts of the bilingual lexicon suppose regulation of the system by modification and control of the level of activation of its languages. In order to speak one language rather than another, its activation level must exceed that of the other language (e.g. Grosjean, 1988, 1997; Paradis, 1984). Regulation is achieved through the modification of levels of activation of the language networks, or items within those networks, rather than via a simple switch mechanism (de Bot, 2004).

Models of proactive and reactive control mechanisms have been proposed. Proactive models suggest that the language user will proactively adapt to the language task or situation by setting the activation levels of his/her different languages at the appropriate levels. For example, when L1 words have to be translated in L2, a language user may adapt to this task by setting the activation level of L1 units clearly above zero, but lower than the activation level of the L2 elements. 'Both languages must be activated to some extent because translation involves both of them, but the output language should be activated more than the input language' (de Groot, 1998).

Paradis $(1984,1997)$ articulated the basic form of this proactive control conjecture in terms of the activation threshold hypothesis, which he relates to the speaker's intention. The intention to speak one language rather than another leads to the raising of the activation threshold of the other language system, but not to its total inhibition, and this may lead to transfer lapses. Grosjean $(1988,1998,2001)$ considers that cross-linguistic influence is related to the specific context in which communication takes place, including the interlocutors (bilingual or monolingual), the setting and the topic of 
conversation. These factors proactively determine the relative position of language production as close to the bilingual or the monolingual mode, so that if the speaker adopts a bilingual mode, his/her production is more likely to present more cross-linguistic influence (Cenoz, 2003: 107). In the bilingual mode, when individuals are speaking with others with whom they can codeswitch or mix languages, bilinguals adopt one language as the base or matrix language and bring in the other language when required as a 'guest' language. As a consequence, both languages are relatively active, but the base language is more strongly activated. In the BIA model, Dijkstra and Van Heuven (1997) view the resolution of competition between word candidates in both languages as differentially inhibited top-down on the basis of language nodes, an idea which is echoed in Poulisse and Bongaert's (see Poulisse, 1997) adaptation of Levelt's language production model (1989) to the bilingual case, where the goal to produce one language and not the other is reached by installing a language cue as one of the conceptual features in the conceptual representation. Common to these last two models is the conviction that language nodes or cues can be preactivated reflecting a particular task. The BIA model views responses as a function of the task situation, the nature of the stimulus materials, as well as the expertise of the bilingual. Language nodes are analogous to a control schema in that they are external to the system under regulation, are governed by a higher-order system, modulate the activity of units within the system top-down, and can, thus, be proactively adapted to the task (de Groot, 1998).

In contrast to these proactive models, in his multiple level inhibitory control model (1998), Green proposes retroactive regulation by language task schemas. Unique in Green's model seems to be the assumption that the language task schemas, constructed and controlled by the 'Supervisory Attentional System', operate retroactively rather than proactively upon the level of activation of the units in the bilingual lexico-semantic system proper. For instance, if the subject's task is to translate L1 words into L2, activated L1 lemmas must be inhibited if their names are not to pop out inadvertently as responses. The task schema dominant under the prevailing circumstances, the L2 production schema, takes care of this by reactively suppressing the level of activation of the lemmas with an L1 label. If, on the other hand, the subjects must name pictures in L1, an L1 production schema must, again reactively, suppress the elements with an L2 language tag and enhance those with an L1 tag.

Proactive task adaptation seems more efficient than the retroactive regulation by language task schemas. When the activation levels of the memory nodes in the bilingual system are proactively adapted to the specific goals of the subject (that is, prior to the onset of task performance and perhaps immediately on receiving task instructions), the representational elements that belong to the contextually inappropriate language may generally not be activated enough to become available in the first place, and no mental energy will thus have to be wasted in preventing them from being produced as output. In contrast, in a retroactive system, both the contextually appropriate and the contextually inappropriate memory nodes will often be available, requiring active suppression of the latter, a process that is likely to consume mental energy. 
Where individuals are consistently translating from one direction to another, the controlling schema is in place and the extent of cross-linguistic influence will probably be limited. However, if there is a change of language, as in the task in our study, the translation task schema may still be in place, but any lemmas in the previously active target language will have to become inhibited. Here, it seems necessary to assume a reactive control mechanism.

\section{(3) Reasons for and variables affecting cross-linguistic influence}

From what has been previously stated, it can be concluded that items from different languages may be activated in parallel and will be inhibited at a given point in time in the production or comprehension process when they do not meet the expected features. The language activation control system has been conceived of in different ways and as working proactively or reactively. Contextual and task features have been shown to affect the level of language activation of the different languages in the multilingual brain. When language activation and inhibition are at appropriate levels, no cross-linguistic influence will occur, as, indeed, is the case in most instances of language production and comprehension.

However, evidence of cross-linguistic influence also abounds (see Cenoz et al., 2003 for a recent collection of papers demonstrating this), for which many different reasons have been suggested. They include the inappropriate application of contextual or language task features (as highlighted above), the speaker's deliberate intention to codeswitch (Cenoz, 2003), the underrepresentation of particular lexical items in the lexicon or the wrongful storage of the item on its acquisition (Hall \& Ecke, 2003), the insufficiently strong intralingual connections between words (Kempe \& MacWhinney, 1996), or, still, the fact that the task demands in themselves leave insufficient attentional capacity for (retroactive) language production monitoring (de Groot, 1998).

The conditions under which cross-linguistic influence occurs in bi-, tri- or multilinguals have been the object of considerable study. A number of possible (and potentially interacting) factors have been identified, and may be grouped into five domains (Hall \& Ecke, 2003: 72-73): (1) learner factors, which distinguish variation between individuals and include factors, such as motivation, self-perceived proficiency or perceived typological distance between languages (psychotypology; Kellerman, 1983); (2) learning factors, to do with the history and context of the acquisition process, including the order and time-course of learning, the proficiency in each language, or the amount of language use; (3) language factors, concerned with the nature of the languages involved and the formal relations between them (extent of typological similarity; L2 status); (4) event factors, involved in actual situations of use, such as language mode, style (formal/informal) or task (free, test, translation, etc.); and, finally, (5) word factors, i.e. relevant characteristics of the specific words involved (e.g. degree of frame similarity (lemma) with competitors; content word versus function word status; abstractness versus concreteness; frequency; recency of exposure or use).

Even if, at present, the specific contribution of these different factors to a theory of cross-linguistic influence is unclear, also because it has appeared 
extremely difficult to investigate these different variables in isolation, several factors have repeatedly been shown to be important correlates of CLI, namely L2 proficiency level, typology, recency of use and L2 status (Hammarberg, 2001; Williams \& Hammarberg, 1997, 1998). As regards typology, research studies have shown that learners tend to transfer more elements from the first language when it is typologically close to the target language than when it is a distant language, and interview studies based on self-reports confirm this trend (Hufeisen 2000; Missler, 2000). Other results have shown that L2 status is important, and that a high status languages will more often serve the role of supplier language in cross-linguistic influence than languages with a lower status. However, when the languages involved are typologically distant and present important differences at the lexeme and lemma levels, the effect of typology will be stronger than the effect of L2 status (Cenoz, 2003). As far as proficiency is concerned, according to Poulisse and Bongaerts (1994) and Hammarberg (2001), for example, cross-linguistic influence is more common in the first stages of acquisition. Nevertheless, the relatively low number of transferred items found in Cenoz (2003), for example, and the positive correlation between cross-linguistic influence and proficiency in the first stages of L3 acquisition (Cenoz, 2001) point toward the existence of a threshold level of proficiency, as suggested by de Angelis and Selinker (2001) and de Bot (1992). Finally, languages that are used frequently and have been used recently will more often feature in cross-linguistic influence than languages, which are used less often and have not been activated recently (Hammarberg, 2001; Williams \& Hammarberg, 1998).

\section{A Research Study}

In the investigation we report on here, we asked learners who were learning multiple foreign languages at school, to translate a text which they had written in their mother tongue into the different foreign languages they knew.

The major questions that guided our investigation were:

(1) When performing a translation task, do the participants manage to keep their languages apart? Are they able to activate one foreign language and prevent other languages, i.e. their L1 or the other foreign languages they know, from affecting target language production?

(2) In case of cross-linguistic influence between languages, do the learners mainly resort to their mother tongue or do they also resort to their other languages, inadvertently or to make up for lexical gaps?

(3) As regards the way in which learners use their multiple languages to make up for lexical gaps, do loanwords occur more frequently than loanblends or literal translations, or are no such differences obvious?

(4) To what extent do a number of variables, which have been shown to affect the extent of cross-linguistic influence in bilinguals appear to correlate with the extent of cross-linguistic influence. The factors we will focus on in some detail are perceived linguistic distance, which has been termed 'psychotypology' (Kellerman, 1983), perceived language proficiency, which we will term 'psychoproficiency', and specific 
language combination. We will also ask the question, to what extent the specific task given to the learners appears to have affected target language production.

\section{Methodology}

\section{Subjects}

The data were collected in 2004 in two Dutch-speaking schools in Brussels. A total of 55 pupils participated in the experiment, aged 17 or 18 , and attending the final year of secondary education. A total of $45.5 \%$ were mother tongue speakers of French, 34.5\% were mother tongue speakers of Dutch, and the others had other mother tongues, namely, Russian, Ga (spoken in Ghana), Albanian, Turkish, Moroccan, Arabic, Spanish, Italian, etc. The most common language combinations in our sample were Dutch-French-English-German and French-Dutch-English-German. ${ }^{1}$ All French mother tongue speakers said they considered Dutch to be their first foreign language. All Dutch mother tongue speakers said their first foreign language was French.

In a written questionnaire, the respondents indicated that they used French and Dutch frequently, both actively and passively. When these languages were said to be the second or third foreign languages, they were also reported to be used frequently. This is most probably due to the fact that the pupils attended a Dutch-speaking school in Brussels, which is situated in a French-speaking neighbourhood. When travelling to school, the Dutch mother tongue speakers encountered shops where French was spoken, signs and ads in French, people speaking French, etc. The French mother tongue speakers used, or were supposed to use, Dutch all the time while at school. English was mainly used passively, especially when watching television, listening to music, playing or reading on the Internet. German was only used passively and far less frequently than English.

From 5-point motivation scales in the questionnaire, we also learned that the pupils' motivation to learn French was high, and, on average, higher than that for learning English or German. This is a tendency which is contrary to what we found to be true in the rest of Flanders, the Dutch-speaking part of Belgium, where pupils tended to be more motivated to learn English than to learn French (Sercu et al., 2005).

On the basis of our analysis of the learner texts produced within the context of this study (cf. infra), we could conclude that the learners' proficiency in French as a foreign language and Dutch as a foreign/second language is high, that in English at an intermediate level and that in German low, not far above a beginners' level.

\section{Data collection}

The data were collected by means of a written questionnaire and a writing and translation task. Via the questionnaire, the respondents provided some personal data (e.g. age, section of education, sex), as well as information on their linguistic and language learning background (the different languages they knew; the frequency with and the contexts in which they used them; their 
perceived proficiency in each of these languages; their motivation to learn the languages offered at school).

The writing task consisted in the composition of a story on the basis of a cartoon in the language which the learner considered his/her mother tongue. The translation task consisted in the translation of that same story into the learner's different foreign languages. The data were collected during two consecutive teaching periods. The participants first completed the questionnaire, which took about 10 minutes. The rest of the time, between 60 and 90 minutes, was devoted to the translation task. The cartoon was about a boy who was hit by a car and had to have his leg put in a cast, and elicited an informal account of the accident. When writing the source text, for which an average length of 20 lines was set, the participants did not know that they would have to translate that text into their different foreign languages. Thus, we wanted to prevent them from writing more simple texts and avoiding difficult words out of fear that they would not be able to translate these later on.

On writing their story, the respondents were told to translate their text into the different foreign languages they knew, starting with the translation into the foreign language they thought they mastered best, continuing with the language they thought they mastered second best, and so on. For the mother tongue speakers of Dutch, this meant, in most cases, that the Dutch text was translated into French first, then into English and finally into German, and for the French speakers that the French source text was translated first into Dutch, then into English, and finally into German. This order coincides with the order in which these different foreign languages are normally taught in schools in Belgium. Through granting the pupils the opportunity to choose the order of the languages into which they translated the text, we thought we would respect the level of activation of these different languages in the learner's multilingual brain. Foreign languages which are mastered well tend to be the most highly activated languages. We instructed the pupils to translate each word or chunk and to try and find a solution if they did not have the translation equivalent readily available. In a sense, the translation task thus provoked cross-linguistic influence, but learners could also opt for circumscriptions or for using near synonyms of the words they were lacking. Even if the amount of transfer in our corpus may have been somewhat inflated through our task instruction, we believe it did not affect the way in which the learners' languages would normally interact when confronted with a lexical gap.

\section{Data analysis}

The experimental data obtained were analysed for level of proficiency ${ }^{2}$ and with a specific focus on issues of cross-linguistic influence. Here, we will mainly focus on the data concerning cross-linguistic influence. We were interested in phenomena, such as loanwords, literal translations and loanblends, and have thus confined our study of cross-linguistic influence to negative transfer. ${ }^{3}$ Loanwords are words which are borrowed from a language and used as such in the foreign language, without morphemic substitution or adaptation. Loanblends show partial morphemic adaptation, whereas literal translations can be identified as copying the words and structure of the source 
Table 1 Examples of loanwords

\begin{tabular}{|l|l|}
\hline Learner production & Correct term \\
\hline The nurse give him a spuitje (D1-E3) & injection \\
\hline All the children wuiven to him (D1-E3) & wave \\
\hline His mother visited him and brought him a beer (D1-E3) & bear \\
\hline He could remove his gips (D2-E3) & cast \\
\hline
\end{tabular}

$\mathrm{D}=$ Dutch, $\mathrm{E}=$ English, 1 = first language/mother tongue, 2 = second language/first foreign language, $3=$ third language/second foreign language.

Table 2 Examples of loanblends

\begin{tabular}{|l|l|l||}
\hline Source language: French & Source term & \multicolumn{1}{|c|}{ Correct term } \\
\hline You don't know how they trait me here (F1-E3) & traiter & treat \\
\hline $\begin{array}{l}\text { At the hospital, docter Marchand diagnostics } \\
\text { (F1-E3) }\end{array}$ & diagnostiquer & diagnosed \\
\hline There is a heart desinate on his gips (F1-E3) & dessiner & drawn \\
\hline A car that rules too fast (F1-E3) & rouler & drives \\
\hline One week later he may retired his gips (F1-E3) & retirer & take off \\
\hline $\begin{array}{l}\text { After the examination of the doc, he } \\
\text { constated ... (F1-E3) }\end{array}$ & constater & diagnoses \\
\hline The conductor of the car also came (F3-E2) & conducteur & driver \\
\hline He was hit by a fast chauffered car (F2-E3) & chauffer & driven \\
\hline Source language: Dutch & & \\
\hline He can jump of the street to ontwiked a car (D1-E3) & ontwijken & avoid \\
\hline To give him a spat (D1-E3) & spuitje & injection \\
\hline The teacher ren to him to see (D2-E3) & rennen: rende & ran \\
\hline A little boy has been over ride (D2-E4) & overreden & run over \\
\hline We are going to do you a spoth (D2-E4) & spuitje & injection \\
\hline He stakes over without looking (D3-E4) & oversteken & crosses the street \\
\hline
\end{tabular}

$\mathrm{D}=$ Dutch, $\mathrm{E}=$ English, 1 = first language/mother tongue, $2=$ second language $/$ first foreign language, 3 = third language/second foreign language, etc.

language and translating these word-by-word into the foreign language, with full morphemic adaptation. In Tables 1-3, we give examples of each of these types of transfer, which have all been taken from the learner texts written in English, although our corpus also contains examples relating to the participants' other languages. Between brackets, information is given regarding the specific source and target language concerned each time. 
Table 3 Examples of literal translations

\begin{tabular}{|l|l|}
\hline & \multicolumn{1}{|c|}{ Source phrase } \\
\hline Thijs $^{\mathrm{a}}$ is in sleep (D1-E3) & Thijs is in slaap \\
\hline He ran without watching over the street (D1-E3) & Hij liep zonder kijken over de straat \\
\hline Where have you pain? (D2-E3) & Waar heb je pijn? \\
\hline I feel me not so good (D2-E4) & Ik voel mij niet zo goed \\
\hline
\end{tabular}

$\mathrm{D}=$ Dutch, $\mathrm{E}=$ English, 1 = first language/mother tongue, $2=$ second language $/$ first foreign language, 3 = third language/second foreign language, etc.

${ }^{a}$ 'Thijs' is the name of the boy in the cartoon.

Table 2 provides examples of loanblends. The first series uses French as the source language. This may be French as a mother tongue or French as a second or foreign language. The second series concerns examples with Dutch as the source language, either as the learner's mother tongue or as a second or third language.

\section{Results}

Our data provide evidence for the simultaneous activation of more than two languages in the multilingual brain. We will focus successively on the extent of cross-linguistic influence, the languages that appear to function as source languages for cross-linguistic transfer, the transfer strategies which learners seem to prefer and, finally, a number of learner variables that appear to affect the extent of cross-linguistic influence.

\section{(1) Limited extent of cross-linguistic influence}

We found the number of cross-linguistic instances found in our corpus to be relatively small $(n=186)$. This means that, even if different language items may be in competition when they are first activated, i.e. when the learner starts the word translation task, the control mechanisms necessary to produce the correct language item appear well in place. The fact that we used written translations, not oral ones, may have helped to keep the extent of crosslinguistic influence limited, since the more extended time-course available for language production in writing, compared to in speaking, increases the chance that the control mechanism will be able to inhibit particular items on time.

As pointed out before, we instructed the learners to translate every word or chunk and to find a solution if they did not have the lexical item available which they needed to achieve this goal. Although our corpus indeed contains instances of creative solutions, most apparent in the loanblends which learners produced, we had hoped to find more of them and fewer 'blanks', i.e. untranslated words, in the translations. The many blanks in the German translations suggest that a threshold level of language knowledge and of intralingual connections are needed before learners can and are willing to take recourse to (typologically related) languages they master better to make up for 
gaps in their lexical knowledge. German was the third foreign language for most respondents, and their proficiency in that language tended to be low, not above a beginners' level. As the translation into German came last for most respondents, they may have been too tired or bored with the translation task to be able or willing to make extra efforts and come up with a creative solution to fill the gaps in their German lexicon. Another reason why a large part of the German translations remained, sometimes largely, unfinished may have been due to the fact that the other languages, previously activated, had pushed German words, with their already weak grounding because of the recency of their acquisition, into the background of their multilingual mind (Kempe \& MacWhinney, 1996). It may, therefore, have been the case that words, which the learner would normally have been able to supply, now remained largely inaccessible.

\section{(2) Is the mother tongue the main source of cross-linguistic influence or can second, third and consecutive languages also fulfil this role?}

From Table 4 , it can be seen that about $54 \%$ of all interlingual mistakes $(n=186)$ can be traced back to the learner's mother tongue. When learners invent a new word or a phrase to make up for a gap in their lexicon, they will first resort to their mother tongue. This finding does not come as a surprise, given the fact that the participants had to translate a source text written in their mother tongue into the different foreign languages they knew. Previous studies have also frequently highlighted the importance of L1 in cross-linguistic influence (e.g. de Angelis \& Selinker, 2001; Ringbom, 2001).

What comes as a surprise though, is that no less than $46 \%$ of the instances of cross-linguistic influence in our corpus provide evidence of the simultaneous activation of three languages. When translating a text from their L1 into one of their foreign languages, other non-target foreign languages appear to have

Table 4 Extent of cross-linguistic influence from L1

\begin{tabular}{|l|c|c||}
\hline & $\begin{array}{c}\text { Number of instances } \\
\text { of cross-linguistic error } \\
\text { from L1 }\end{array}$ & $\begin{array}{c}\text { Percentage of total number } \\
\text { of cross-linguistic errors in } \\
\text { corpus (n =186) }\end{array}$ \\
\hline Dutch L1: Total & 38 & $20.43 \%$ \\
\hline Into French & 8 & $4.30 \%$ \\
\hline Into English & 26 & $13.98 \%$ \\
\hline Into German & 4 & $2.15 \%$ \\
\hline French L1: Total & 62 & $33.33 \%$ \\
\hline Into Dutch & 32 & $17.20 \%$ \\
\hline Into English & 26 & $13.98 \%$ \\
\hline Into German & 4 & $2.15 \%$ \\
\hline
\end{tabular}


been activated as well to a level that has made them surface in the target language text (see Table 5 for the number of instances of this phenomenon in our corpus).

When considering Tables 4 and 5 together, it can be seen that Dutch as a mother tongue, French as a mother tongue and Dutch as a foreign language are the main source languages used to make up for lexical gaps in target language knowledge. French as a foreign language, and, especially English, show influence from Dutch as a mother tongue. Influence from French mother tongue is most obvious on Dutch and English as foreign languages. English is also relatively frequently affected by Dutch as a foreign language.

The fact that English as a foreign language shows influence from Dutch as a mother tongue is not surprising, given the linguistic closeness of these two languages, which appears to be clearly perceived as such by the Dutch mother tongue speakers.

The situation for the French mother tongue speakers is more complex and less straightforward. Though French and English are normally considered as belonging to different linguistic families, with French being considered a Romance language and English a Germanic language, English and French also share an important part of their vocabularies. As our data reveal, this suggests to the language learners that they can reliably use their mother tongue, French, as a source of help when confronted with a lexical gap in English. However, our data also reveal that the French mother tongue speakers, being educated in a Dutch-speaking school, have also come to realise that it may sometimes be helpful to resort to Dutch, their second language, as a source of help for

Table 5 Extent of cross-linguistic influence between foreign languages (FL)

\begin{tabular}{|l|c|c||}
\hline & $\begin{array}{c}\text { Number of instances } \\
\text { of cross-linguistic error } \\
\text { from L1 }\end{array}$ & $\begin{array}{c}\text { Percentage of total number } \\
\text { of cross-linguistic errors in } \\
\text { corpus (n =186) }\end{array}$ \\
\hline In Dutch FL & 5 & $2.69 \%$ \\
\hline From English FL & 9 & $4.84 \%$ \\
\hline From French FL & & \\
\hline In French FL & 2 & $1.08 \%$ \\
\hline From English FL & 1 & $0.54 \%$ \\
\hline In English FL & 5 & $2.69 \%$ \\
\hline From German FL & 26 & $13.98 \%$ \\
\hline From French FL & & \\
\hline From Dutch FL & 9 & $4.84 \%$ \\
\hline In German FL & 29 & $15.59 \%$ \\
\hline From English FL & & \\
\hline From Dutch FL & & \\
\hline
\end{tabular}


producing English, which corroborates the findings of Dewaele (1998). Our corpus contains five instances of literal translation from Dutch L2 into English L3 (e.g. Where have you pain?; I feel me not so good.) produced by F1 speakers, which reveals that these French L1 speakers believe that Dutch and English are syntactically closer to each other than French and English. A final element in the explanation for the about equal share of influence from French L1 and Dutch L2 on English, can be that French and Dutch also share a part of their vocabulary (e.g. French constater $=$ Dutch constateren; French piquire $=$ Dutch pikuur (colloquial); French diagnostiquer = Dutch diagnosticeren; French injection = Dutch injectie). Considering these aspects together, it is probable that the psychotypological picture in the French L1 speaker's mind, learning English in a Dutch L2 environment, is far from clear.

A final finding that surprised us concerns the number of instances $(n=32)$ of transfer from French L1 to Dutch L2. We believe this finding has to be related to the fact that codeswitching between French L1 and Dutch L2 is common in an environment where a foreign language is used as the medium of instruction. It may also be that learners have grown somewhat less attentive to the possibility of negative cross-linguistic influence in such an environment.

Whereas Tables 4 and 5 contain language-specific data, in Table 6, all mother tongues (L1) and all foreign languages (L2, L3, L4, L5) are presented as source and target languages, irrespective of the particular language each time concerned. We can see that L1 acts as a source language for L2, L3, L4 and L5, but also that L2 takes up this same role with respect to L3, L4 and L5, as does L3 with respect to L2 (reverse transfer), L4 and L5, and L4 with respect to L2 (reverse transfer) and L5. The conductor of the car also came (F3 (conducteur) in E2) illustrates this pattern of reverse transfer of a less well-mastered language to a better-mastered language. It is interesting to note that L2 was adduced more often than L1 to make up for lexical gaps in L4 and L5, and that the same is true for L3 with respect to L5. These findings confirm the important influence of the L1, but also highlight the importance of L2 and L3, corroborating the findings put forward in, for example, Schmidt and Frota (1986), Selinker and Baumgartner-Cohen (1995), Dewaele (1998) and Williams and Hammarberg (1998).

The specific example of reverse transfer we have just provided illustrates the complexity of interpreting transfer phenomena as the number of possibly contributing languages grows. The example might be interpreted as an example of a loanblend, where the French conducteur has been morphologically adapted to the matrix language, English. It might also be interpreted as an example of a loanword (English conductor), but one where the meaning (someone who directs an orchestra) has not been transferred correctly. The first explanation seems more plausible to us, though only introspective data could provide a decisive answer here.

Though reverse transfer errors did not occur frequently in our corpus $(n=9)$, we want to speculate here about the way in which the translation task may have contributed to their production. Is knowing that one will have to use one of one's foreign languages later on, sufficient to activate that language's lemmas in the multilingual brain? Because of the limited number of instances of reverse transfer we obtained, it seems that, even if this were the case, the 
Table 6 Interlingual mistakes: relative proportions of cross-linguistic influence from L1, L2, L3 and L4 to L1, L2, L3, L4 and L5

\begin{tabular}{|l|c|c|}
\hline & $\begin{array}{c}\text { Number of instances } \\
\text { of cross-linguistic influence }\end{array}$ & $\begin{array}{c}\text { Percentage of total number } \\
\text { of cross-linguistic errors in } \\
\text { corpus } \mathbf{( n = 1 8 6 )}\end{array}$ \\
\hline L1 to L2 & 34 & $18.38 \%$ \\
\hline L1 to L3 & 48 & $25.95 \%$ \\
\hline L1 to L4 & 15 & $8.11 \%$ \\
\hline L1 to L5 & 3 & $1.62 \%$ \\
\hline L2 to L1 & 1 & $0.54 \%$ \\
\hline L2 to L3 & 21 & $11.35 \%$ \\
\hline L2 to L4 & 21 & $11.35 \%$ \\
\hline L2 to L5 & 15 & $8.11 \%$ \\
\hline L3 to L1 & 0 & $0.00 \%$ \\
\hline L3 to L2 & 9 & $4.86 \%$ \\
\hline L3 to L4 & 7 & $3.78 \%$ \\
\hline L3 to L5 & 6 & $3.24 \%$ \\
\hline L4 to L1 & 0 & $0.00 \%$ \\
\hline L4 to L2 & 2 & $1.08 \%$ \\
\hline L4 to L3 & 0 & $0.00 \%$ \\
\hline L4 to L5 & 3 & $1.62 \%$ \\
\hline & & $100 \%$ \\
\hline
\end{tabular}

multilingual's control mechanism, suppressing words with the wrong language cues, works well in almost all cases. When reverse transfer occurs this may, to our mind, be related to the fact that specific lemmas with complex intralinguistic and/or cross-linguistic semantic and/or formal links are preeminent candidates for being involved in this kind of transfer, a suggestion also made in Herwig (2001).

\section{(3) Do learners use loanblends more often than borrowing or literal translation?}

Our data reveal that loanblends (38.32\%) and loanwords (41.92\%) make up an approximately equal proportion of the cross-linguistic mistakes observed in our corpus, as opposed to $19.76 \%$ for literal translations.

When considering these findings in relation to the source and target languages (Table 7), we found that learners will borrow less from their mother tongue than from other foreign languages, and that loanblends and literal 
Table 7 Loanwords, loanblends and literal translations in relation to target and source languages

\begin{tabular}{|l|c|r|r|r|r|r||}
\hline & \multicolumn{2}{|c|}{ Loanwords } & \multicolumn{2}{c|}{ Loanblends } & \multicolumn{2}{c|}{ Literal translations } \\
\hline L1 to L2 & 7 & & 8 & & 13 & \\
\hline L1 to L3 & 13 & & 20 & & 10 & \\
\hline L1 to L4 & 5 & & 8 & & 2 & \\
\hline L1 to L5 & 0 & & 2 & & & \\
\hline L1 to FL & 25 & $39.68 \%$ & 38 & $56.72 \%$ & 25 & $75.76 \%$ \\
\hline L2 to L3 & 8 & & 9 & & 3 & \\
\hline L2 to L4 & 7 & & 4 & & 4 & \\
\hline L2 to L5 & 5 & & 9 & & & \\
\hline L3 to L2 & 8 & & 1 & & & \\
\hline L3 to L4 & 3 & & 4 & & & \\
\hline L3 to L5 & 5 & & & & & \\
\hline L4 to L2 & 2 & & & & & \\
\hline L4 to L5 & 0 & & 2 & & 1 & \\
\hline FL to FL & 38 & $60.32 \%$ & 29 & $43.28 \%$ & 8 & $24.24 \%$ \\
\hline Total & 63 & $100 \%$ & 67 & $100 \%$ & 33 & $100 \%$ \\
\hline
\end{tabular}

translations can be traced back more often to the L1, as is obvious from Table 4, although as pointed out earlier, the French L1 speakers also appeared repeatedly to translate literally from Dutch L2 into English. This suggests that when borrowing words, learners operate under a monolingual 'write foreign' mode (de Angelis \& Selinker, 2001; Hufeisen, 2000b; Meisel, 1983). With respect to content words, they tend to de-activate their mother tongue, realising, most of the time at least, that borrowing from that language is not allowed. By contrast, function words are quite frequently borrowed from the mother tongue, which suggests that they more easily escape the attention of the language monitor than content words (Poulisse \& Bongaerts, 1994).

Our data suggest that language learners use these three transfer strategies in different ways. Literal translations appear to be used only when a learner feels his proficiency in the source language is high enough, since we have no instances in our corpus of literal translations from L3, L4 or L5, only from L1 and L2. Loanblends occur when learners feel they have mastered the morphology and syntax of the target language well enough and in case of perceived typological closeness. The use of loanwords, finally, seems to be determined foremost by the learner's perception of the linguistic distance between the languages involved. Without introspective data, we have to remain cautious about the validity of these claims. 


\section{(4) Do psychoproficiency and specific language combination affect the extent of cross-linguistic influence?}

Until now we have focused on a number of general patterns, which show that the different languages in the multilingual brain are linked to each other in complex ways, and that learners may use different strategies when faced with a lexical gap. We will now focus on a number of learner variables - apart from psychotypology, which has already been commented on - and investigate whether these variables appear to affect the extent of crosslinguistic influence in the multilingual learner. They concern the learners' perception of their mastery of a language (psychoproficiency) and their specific language combination.

\section{(a) Psychoproficiency}

In studies of multilingualism, language proficiency is frequently mentioned as a factor affecting the degree of cross-linguistic influence in language production (e.g. Cenoz et al., 2003; Hammarberg, 2001; Williams \& Hammarberg, 1997, 1998). The more proficient a learner is in a particular language, the less cross-linguistic influence will occur. In our study, the main indicator of actual proficiency used was the number of linguistic (intralinguistic ${ }^{4}$ and cross-linguistic) mistakes observed in the written texts (source text and translations of the source text). Our data show that the amount of intralinguistic errors is positively and significantly related to the extent of interlinguistic errors $(n=150, r=0.610, p=0.000)$, which suggests that fewer instances of cross-linguistic influence will indeed be observable in better mastered languages. Our findings also show that the learners' perception of the order of proficiency in their different languages (i.e. psychoproficiency ${ }^{5}$ ) is not reflected in the overall extent of intralinguistic $(p=0.483)$ or cross-linguistic $(p=0.160)$ mistakes. In other words, the researcher's perception of proficiency is better related to the extent of crosslinguistic influence than the learner's perception. Learners appear to determine mastery foremost in terms of communicative ability, and less in terms of morphogrammatical or lexicogrammatical correctness. Thus, psychoproficiency does not appear a reliable indicator of the extent of cross-linguistic influence in the multilingual lexicon, whereas actual proficiency does.

\section{(b) Specific language combination}

About half of our respondents $(n=30)$ either had the language combination Dutch-French-English (DFE) or French-Dutch-English (FDE). Some 19 respondents also had this combination, but combined with one or several additional languages, which were L1's in some cases and L2's, L3's, L4's or L5's in others. Four respondents had the combination English-Dutch-French and two English-French-Dutch. Due to the large diversity of language combinations, we decided not to include the latter three groups in the analysis, but rather focused on the DFE and the FDE groups. From Table 8, it can be seen that the groups do not differ significantly with respect to the extent of cross-linguistic influence $(F(5,227), t-1.446, p=0.159)$, even if group means are higher in the second than in the first group (4.94 as opposed to 2.86). The standard deviations are considerable (3.110 and 4.524 in Group 2), indicating that some 


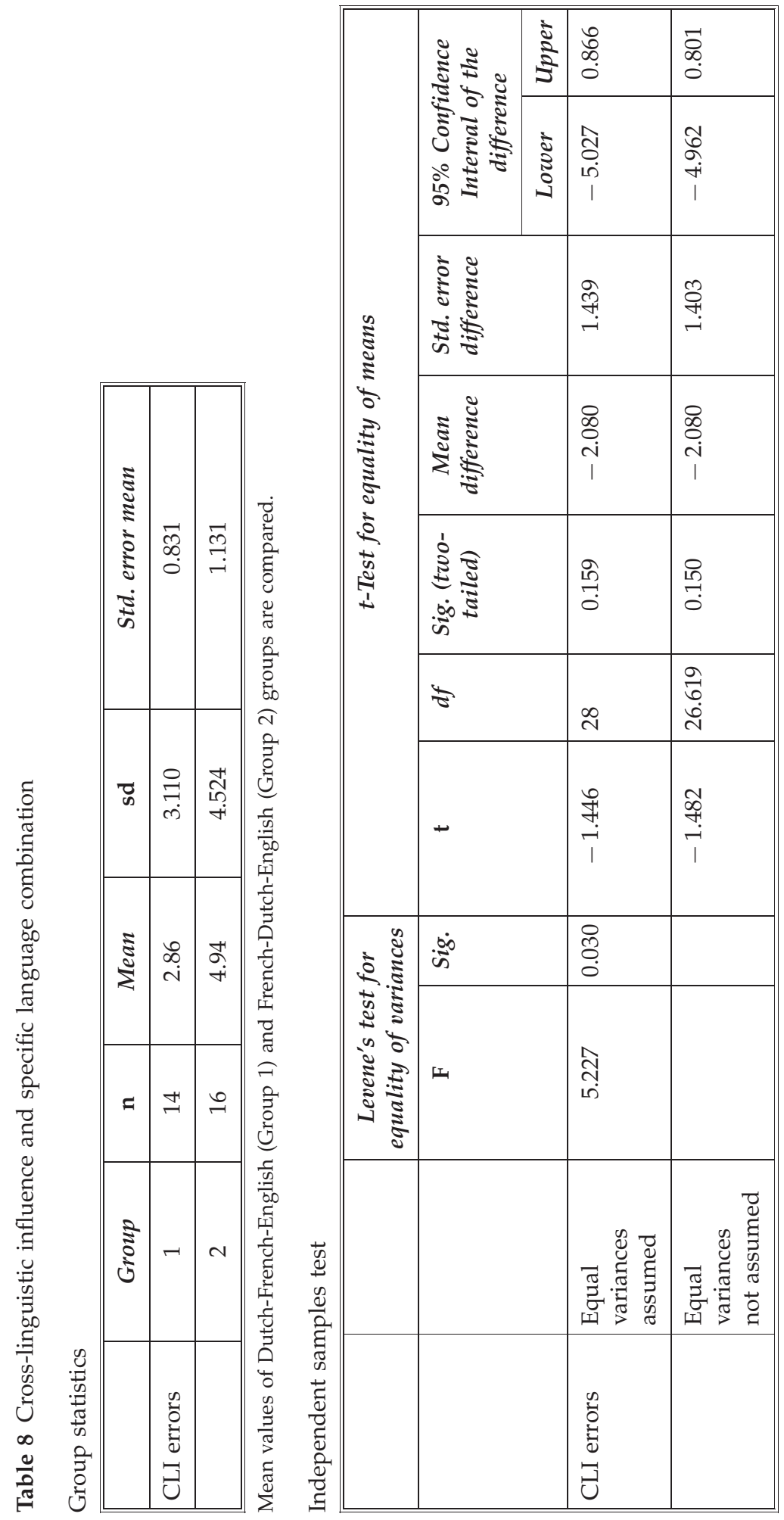


individuals' texts contained a large number of mistakes in comparison to those of others, with numbers ranging between 13 and 0 .

These findings thus suggest that, in this particular case, language combination cannot be considered a good predictor of the extent of crosslinguistic influence. The standard deviations, in addition, suggest that large individual differences exist between learners. Whether these differences can be traced back, for example, to differences in the history or context of acquisition, or to differences in the interpretation of the task demands, to name just these variables which have been mentioned as variables that can potentially affect the extent of cross-linguistic influence (Hall \& Ecke, 2003), has to remain a matter of speculation for now, and further research is needed to investigate these factors in isolation and in combination with other learner variables.

\section{Conclusion}

Our data show that multilingual language learners basically manage proactively to adapt their multilingual lexicon to the demands of a translation task, activating the appropriate target language items most and setting the L1 and other non-target foreign languages to levels that prevent them from surfacing. When cross-linguistic influence occurs, learners appear to take on a mainly bilingual mode. The languages, which are activated, may be the mother tongue and a foreign language; they may also be two foreign languages. It is mainly the better-mastered foreign languages that are used as sources of help when confronted with a lexical gap, though we also have instances of reverse transfer, where less well mastered languages have caused cross-linguistic errors in better-mastered languages. We have also tentatively suggested that learners appear to use literal translation, loanwords and loanblends in different ways, depending on the way in which they perceive their proficiency in the different foreign languages they master. Finally, we have shown that a number of learner variables appear to affect the extent of cross-linguistic influence, notably actual proficiency psychotypology, and that others, namely the specific language combination and psychoproficiency, do not. Finally, we have shown that the learner's perception of psychotypology may be unclear and that this may result in insufficient daring to use a particular language as source language as well as in unnecessary crosslinguistic errors.

Our findings confirm that a number of tendencies appear to be common to all multilinguals, but also that the level of activation of any interlanguage and of specific lemmas in the multilingual brain, may be triggered by factors internal and specific to the learner. Depending on the learner's specific language learning history, task perceptions or perceptions of contextual features, one learner's version of a language may be very different from that of another learner as well as from the language as it is described by linguists in grammar books and dictionaries. To bridge the gap between their interlanguages on the one hand and mastery of these different languages on the other, learners need to acquire strategies that will help them to manage their different languages, both in terms of avoidance of mistakes, 
and in terms of making adequate positive use of these languages in language production.

We conclude with a recommendation for further research, related to the specific data collection measure we used in our study. In the past, different research instruments have been employed to gain access to the multilingual brain. In the past, both psycholinguistically oriented laboratory research and research carried out in ecologically valid settings have been used. The specific measures which have been used include reaction time measures (see Dijkstra et al., 1999; Schreuder \& Weltens, 1995; or Singleton, 1999, for many useful examples), analyses of written and spoken language output (e.g. Cenoz et al., 2003; de Angelis \& Selinker, 2001; Dewaele, 1998; Dijkstra, 2003; Hammarberg, 2001; Hufeisen, 2000; Meisel, 1983; Williams \& Hammarberg, 1998), and more recently, think aloud protocols and other kinds of process data (e.g. Gibson \& Hufeisen, 2003; Jessner, 2003). All of these measures have highlighted the complexity of operations in the multilingual brain. Though many of the findings from these studies corroborate each other, these studies have also often yielded contradictory evidence in some respects, and it is clear that much more research needs to be done, replicating existing approaches, but also using still others, and carefully considering to what extent the specific approach taken may affect language production. We agree with de Bot et al. (2005: 165) who write that research is urgently needed into the extent to which the output of activity from the representational system interacts with the processing goals and task demands or the context in which the languages are used. Not understanding how these factors affect language production may lead to faulty conclusions regarding the multilingual mind's underlying architecture. Generalisations about the representational system may be drawn which are, in fact, mediated by task related or context related factors. Following from this suggestion, we want to conclude with the recommendation that the approach to data collection used in this study be replicated in other contexts, and that tasks be used which slightly vary from ours, to gain a better understanding of the extent to which the task format in our study appears to have affected our findings.

\section{Correspondence}

Any correspondence should be directed to Lies Sercu, Faculty of Arts, Katholieke Universiteit Leuven (K.U. Leuven), Blijde-Inkomststraat 21, 3000 Leuven, Belgium (lies.sercu@arts.kuleuven.be)

\section{Notes}

1. We will also largely disregard findings for German here, given the fact that the German translations of the mother tongue text were very often incomplete.

2. In the study, level of proficiency was defined in terms of lexical richness (type/ token ratio) and the number of intralingual and interlingual mistakes in each text. In addition to these quantifiable features, each text was assessed qualitatively by the researcher and assigned a score, ranging from 'beginner' over 'pre-intermediate' and 'intermediate' to 'pre-advanced' and 'advanced'.

3. Thus, we focused only on what Weinreich (1953) termed 'interference'. Contrary to Weinreich, we do not consider native or foreign language influence on other languages learnt solely as an impediment to the acquisition of those languages. 
Rather, we believe negative transfer in a learner's interlanguage can also be viewed as evidence of his/her attempts to achieve his/her communicative goals in a particular foreign language, and thus as something positive. When we use the term 'negative transfer', 'negative' only implies that the transfer has resulted in an error in the target language. Also, in our study, we had no intention of providing data regarding the under- or overproduction of particular structures in the target languages (Odlin, 1989), although we agree with Selinker (1983) and Gass (1983; 1984) that evidence regarding the significance of a particular feature in the learner's L1 is needed in order to strengthen the validity of any claim regarding crosslinguistic influence.

4. For the classification of intralingual mistakes, we made use of the UCL Error Editor, a software package that allows for the assignment of labels to linguistic mistakes. We made the distinction between cross-linguistic errors and intralingual errors. Within the intralingual errors, we distinguished between semantic, syntactic and morphological errors, as in the UCLEE.

5. In the questionnaire, we asked the learners to rate their proficiency in each of the foreign languages they knew. These data yielded the psychoproficiency index, which was used here.

\section{References}

Brysbaert, M. (1998) Word recognition in bilinguals: Evidence against the existence of two separate lexicons. Psychologica Belgica 38, 163-175.

Brysbaert, M. (s.d.) Hoe werkt tweetaligheid? On WWW at www.pc.rhul.ac.uk/staff/ M.Brysbaert/marcbrysPDF/18_Hoe_werkt_tweetaligheid.pdf. Accessed 16.3.2006.

Brysbaert, M., Van Dyck, G. and Van de Poel, M. (1999) Visual word recognition in bilinguals: Evidence from masked phonological priming. Journal of Experimental Psychology: Human Perception and Performance 25, 137-148.

Cenoz, J. (2001) The effect of linguistic distance, L2 status and age on cross-linguistic influence in L3 acquisition. In J. Cenoz, B. Hufeisen and U. Jessner (eds) Cross-linguistic Influence in Third Language Acquisition: Psycholinguistic Perspectives (pp. 8-20). Clevedon: Multilingual Matters.

Cenoz, J. (2003) The role of typology in the organization of the multilingual lexicon. In J. Cenoz, B. Hufeisen and U. Jessner (eds) The Multilingual Lexicon (pp. 103-116). Amsterdam: Kluwer Academic Publishers.

Cenoz, J. and Genesee, F. (1998) Psycholinguistic perspectives on multilingualism and multilingual education. In J. Cenoz and F. Genesee (eds) Beyond Bilingualism: Multilingualism and Multilingual Education (pp. 16-32). Clevedon: Multilingual Matters.

Cenoz, J., Hufeisen, B. and Jessner, U. (eds) (2001a) Cross-Linguistic Influence in Third Language Acquisition: Psycholinguistic Perspectives. Clevedon: Multilingual Matters.

Cenoz, J., Hufeisen, B. and Jessner, U. (eds) (2001b) Looking Beyond Second Language Acquisition. Studies in Tri- and Multilingualism. Clevedon: Multilingual Matters.

Cenoz, J., Hufeisen, B. and Jessner, U. (eds) (2003) The Multilingual Lexicon. Amsterdam: Kluwer Academic Publishers.

De Angelis, G. and Selinker, L. (2001) Interlanguage transfer and competing linguistic systems in the multilingual mind. In J. Cenoz, B. Hufeisen and U. Jessner (eds) Cross-linguistic Influence in Third Language Acquisition: Psycholinguistic Perspectives (pp. 42-58). Clevedon: Multilingual Matters.

de Bot, K. (1992) A bilingual production model: Levelt's speaking model adapted. Applied Linguistics 13 (1), 1-24.

de Bot, K. (2004) The multilingual lexicon: Modeling selection and control. International Journal of Multilingualism 1 (1), 17-32.

de Bot, K., Lowie, W. and Verspoor, M. (2005) Second Language Acquisition. An Advanced Resource Book. London: Routledge. 
de Groot, A. (1992) Bilingual lexical acquisition. A closer look at the conceptual representations. In R. Frost and L. Katz (eds) Orthography, Phonology, Morphology, and Meaning (pp. 389-412). Amsterdam: Elsevier.

de Groot, A.M.B. (1998) Retroactive or proactive control of the bilingual system. Bilingualism: Language and Cognition 1, 86-87.

Dewaele, J-M. (1998) Lexical inventions: French interlanguage as L2 versus L3. Applied Linguistics 19 (4), 471-490.

Dijkstra, T. (1998) From tag to task: Coming to grips with bilingual control issues. Bilingualism: Language and Cognition 1, 51-66.

Dijkstra, T. and Van Heuven, W.J.B. (1998) The BIA model and bilingual word recognition. In J. Grainger and A. Jacobs (eds) Localist Connectionist Approaches to Human Cognition (pp. 189-225). Hillsdale, NJ: Erlbaum.

Dijkstra, T. and van Heuven, V. (2002) The architecture of the bilingual word recognition system. Bilingualism: Language and Cognition 5, 175-197.

Dijkstra, T., Van Heuven, W.J.B. and Grainger, J. (1998) Simulating cross-language competition with the Bilingual Interactive Activation Model. Psychologica Belgica 38, 177-197.

Dijkstra, T., Timmermans, M. and Schriefers, H. (2000) On being blinded by your language. Effects of task demands and language intermixing. Bilingualism: Language and Cognition 1, 51-66.

Gass, S. (1983) Language transfer and universal grammatical relations. In S. Gass and L. Selinker (eds) Language Transfer in Language Learning (pp. 69-82). Rowley, MA: Newbury House.

Gass, S. (1984) A review of interlanguage syntax: Language transfer and language universals. Language Learning 34 (2), 115-131.

Gibson, M. and Hufeisen, B. (2003) Investigating the role of prior foreign language knowledge. In J. Cenoz, B. Hufeisen and U. Jessner (eds) The Multilingual Lexicon (pp. 87-102). Amsterdam: Kluwer Academic Publishers.

Grainger, J. and Dijkstra, T. (1992) On the representation and use of language information in bilinguals. In R. Harris (ed.) Cognitive Processing in Bilinguals (pp. 207-220). Amsterdam: North-Holland.

Green, D.W. (1998) Mental control of the bilingual lexico-semantic system. Bilingualism: Language and Cognition 1, 67-81.

Grosjean, F. (1988) Exploring the recognition of guest words in bilingual speech. Language \& Cognitive Processes 3, 233-274.

Grosjean, F. (1997) Processing mixed language: Issues, findings and models. In A.M.B. de Groot and J.F. Kroll (eds) Tutorials in Bilingualism: Psycholinguistic Perspectives (pp. 225-254). Mahwah, NJ: Lawrence Erlbaum Associates.

Grosjean, F. (1998) Studying bilinguals: Methodological and conceptual issues. Bilingualism: Language and Cognition 1, 131-149.

Grosjean, F. (2001) The bilingual's language modes. In J. Nichols (ed.) One Mind, Two Languages: Bilingual Language Processing (pp. 1-25). Oxford: Blackwell.

Hall, C.J. and Ecke, P. (2003) Parasitism as a default mechanism in L3 vocabulary acquisition. In J. Cenoz, B. Hufeisen and U. Jessner (eds) The Multilingual Lexicon (pp. 71-86). Amsterdam: Kluwer Academic Publishers.

Hammarberg, B. (2001) Roles of L1 and L2 in L3 production and acquisition. In J. Cenoz, B. Hufeisen and U. Jessner (eds) Cross-Linguistic Influence in Third Language Acquisition. Psycholinguistic Perspectives. (pp. 21-41). Clevedon: Multilingual Matters.

Herwig, A. (2001) Plurilingual lexical organisation: Evidence from lexical processing in L1-L2-L3-L4 translation. In J. Cenoz, B. Hufeisen and U. Jessner (eds) Cross-linguistic Influence in Third Language Acquisition: Psycholinguistic Perspectives (pp. 115-137). Clevedon: Multilingual Matters.

Hufeisen, B. (2000) How do foreign language learners evaluate various aspects of their multilingualism? In S. Dentler, B. Hufeisen and B. Lindemann (eds) Tertiär- und Drittsprachen. Projekte und empirische Untersuchungen (pp. 23-39). Tübingen: Stauffenburg. 
Keatley, C., Spinks, J. and de Gelder, B. (1994) Asymmetrical cross-language priming effects. Memory and Cognition 22, 70-84.

Kellerman, E. (1983) Now you see it, now you don't. In S. Gass and L. Selinker (eds) Language Transfer in Language Learning (pp. 112-134). Rowley, MA: Newbury House.

Kellerman, E. (1986) An eye for an eye: Cross-linguistic constraints on the development of the L2 lexicon. In E. Kellerman and M. Sharwood-Smith (eds) Cross-linguistic Influence in Second Language Acquisition (pp. 35-48). New York: Pergamon.

Kempe, V. and MacWhinney, B. (1996) The cross-linguistic assessment of foreign language vocabulary learning. Applied Psycholinguistics 17, 149-183.

Kroll, J.F. and Curley, J. (1988) Lexical memory in novice bilinguals: The role of concepts in retrieving second language words. In M. Gruneberg, P. Morris and R. Sykes (eds) Practical Aspects of Memory (pp. 389-395). London: John Wiley \& Sons.

Kroll, J.F. and Stewart, E. (1994) Category interference in translation and picture naming - evidence for asymmetric connections between bilingual memory representations. Journal of Memory and Language 33, 149-174.

Kroll, J.F. and de Groot, A. (1997) Lexical and conceptual memory in the bilingual: Mapping form to meaning in two languages. In A. de Groot and J.F. Kroll (eds) Tutorials in Bilingualism: Psycholinguistic Perspectives (pp. 201-224). Mahwah, NJ: Lawrence Erlbaum Publishers.

Levelt, W. (1989) Speaking: From Intention to Articulation. Cambridge: MA: Bradford Books/MIT Press.

Missler, B. (1999) Fremdsprachenlernerfahrungen und Lernstrategien. Eine empirische Untersuchung. Tübingen: Stauffenburg.

Myers-Scotton, C. (1993) Duelling Languages: Grammatical Structure in Codeswitching. Oxford: Oxford University Press.

Odlin, T. (1989) Language Transfer. Cambridge: Cambridge University Press.

Paradis, M. (1984) Aphasie et traduction. Meta, Translators' Journal 29, 57-67.

Paradis, M. (1994) Toward a neurolinguistic theory of simultaneous translation: The framework. International Journal of Psycholinguistics 10, 319-335.

Paradis, M. (1997) The cognitive neuropsychology of bilingualism. In A.M.B. de Groot and J.F. Kroll (eds) Tutorials in Bilingualism: Psycholinguistic Perspectives (pp. 331-354). Mahwah, NJ: Lawrence Erlbaum Associates.

Paradis, M. (2004) A Neurolinguistic Theory of Bilingualism. Amsterdam: John Benjamins.

Poulisse, N. (1997) Language production in bilinguals. In A.M.B. de Groot and J.F. Kroll (eds) Tutorials in Bilingualism (pp. 201-224). Mahwah, NJ: Lawrence Erlbaum Associates.

Poulisse, N. and Bongaerts, T. (1994) First language use in second language production. Applied Linguistics 15, 36-57.

Ringbom, H. (2001) Lexical transfer in L3 production. In J. Cenoz, B. Hufeisen and U. Jessner (eds) Cross-linguistic Influence in Third Language Acquisition: Psycholinguistic Perspectives (pp. 59-68). Clevedon: Multilingual Matters.

Schmidt, R.W. and Frota, S. (1986) Developing basic conversation ability in a second language: A case study of an adult learner. In R.R. Day (ed.) Talking to Learn: Conversation in Second Language Acquisition (pp. 237-326). Rowley, MA: Newbury House.

Selinker, L. (1983) Language transfer. In S. Gass and L. Selinker (eds) Language Transfer in Language Learning (pp. 33-68). Rowley, MA: Newbury House.

Selinker, L. and Baumgartner-Cohen, B. (1995) Multiple language acquisition: 'Damn it, why can't I keep these two languages apart?' In M. Bensoussan, I. Kreindler and E. Aogáin (eds) Multilingualism and Language Learning. 8, 2. Language, Culture and Curriculum (pp. 115-123). Clevedon: Multilingual Matters.

Sercu, L., Bandura, E., Castro, P., Davcheva, L., Laskaridou, C., Lundgren, U., Mendez Garcia, M.C. and Ryan, P. (2005) Foreign Language Teachers and Intercultural Communication. An International Investigation. Clevedon: Multilingual Matters.

Singleton, D. (2003) Perspectives on the multilingual lexicon: A critical synthesis. In: J. Cenoz, B. Hufeisen and U. Jessner (eds) The Multilingual Lexicon (pp. 167-176). Amsterdam: Kluwer Academic Publishers. 
Van Heuven, W.J.B., Dijkstra, T. and Grainger, J. (1998) Orthographic neighborhood effects in bilingual word recognition. Journal of Memory and Language 39, 458-483.

Weinreich, U. (1953) Languages in Contact. The Hague, NL: Mouton.

Williams, S. and Hammarberg, B. (1997) L1 and L2 Influence in L3 Production. Stockholm: Stockholm University, Centre for Research on Bilingualism.

Williams, S. and Hammarberg, B. (1998) Language switches in L3 production: Implications for polyglot speaking model. Applied Linguistics 19, 295-333. 